\title{
La necesidad de sensatez y cooperación para el desarrollo sostenible
}

\section{Rafael A. Barrera G.*}

\author{
Reseña de libro \\ Jeffrey D. Sachs (2018). A New Foreign Policy: Beyond American Exceptionalism. \\ New York: Columbia University Press.
}

Un nuevo llamado por el Desarrollo Sostenible hace Geoffrey Sachs ${ }^{1}$, con la atención puesta en los discutidos valores tradicionales en los que se soporta Estados Unidos para establecer su posición de dominio en el mundo, que en la actualidad ponen en duda su capacidad de injerencia en los asuntos del globo con base en las amenazas y su creencia en la supremacía militar. Estados Unidos no es un país inmune a los problemas del planeta en torno al cambio climático, las consecuencias devastadoras de la guerra, y la creciente desigualdad económica. Es uno más y, por tanto, para mejorar su propia situación requiere de la cooperación con otros países y cambiar su política exterior.

Los hechos lo confirman y son más que evidentes. A pesar del avance tecnológico que tiene Estados Unidos ha sido incapaz de contener rápidamente el que se ha considerado el mayor incendio forestal registrado durante el

* Magíster en economía y doctorando en estudios políticos (II año) de la Universidad Externado de Colombia. Profesor de la Escuela Colombiana de Ingeniería Julio Garavito. Bogotá (Colombia) y de la Universidad Colegio Mayor de Cundinamarca, Bogotá (Colombia). [randresbg@yahoo.com], [https://orcid.org/0000-0001-7773-8984].

1 Un trabajo anterior del autor sobre el tema fue lanzado en 2014 y traducido como La era del desarrollo sostenible. En aquella oportunidad señaló que "los Objetivos de Desarrollo Sostenible (oDs) [serían] la diplomacia económica mundial de la próxima generación” (Sachs, 2014, p. 17), en vista del gran crecimiento económico en el planeta y los problemas que el modelo actual de crecimiento tiene en términos de la creciente desigualdad, no solo entre países sino al interior de ellos, y de la crisis ambiental que amenaza con destruir el propio planeta.

Para citar esta reseña:

Barrera G., R. A. (2020). La necesidad de sensatez y cooperación para el desarrollo sostenible. [Reseña Jeffrey D. Sachs (2018). A New Foreign Policy: Beyond American Exceptionalism. New York: Columbia University Press.]. OAsIs, 31, pp. 245-249

DoI: https://doi.org/10.18601/16577558.n31.14 
último siglo en California. De igual manera, los resultados de las elecciones del 6 de noviembre muestran la división del país, en donde las minorías han obtenido triunfos considerados históricos, y en donde se establece un posible nuevo derrotero en la política interior y exterior del país a la luz de los fenómenos migratorios, como el que se vive por parte de los migrantes centroamericanos que se dirigen hacia Estados Unidos. Cabe recordar que aun cuando han existido en Estados Unidos distintas campañas antiinmigrantes, "el discurso supremacista y xenófobo de Trump no es algo nuevo ni caso particular de EUA" (Carrasco, 2017, p. 176).

A lo largo de 19 capítulos hace una crítica a lo que se ha considerado la base de la política exterior de los Estados Unidos, el excepcionalismo. Este constituye la justificación para la intervención militar que, en particular, se destaca por guerras de elección en distintas partes del mundo sin ninguna victoria real y con incontables pérdidas humanas y desastres materiales incalculables que no justifican dichas acciones. De igual manera, ante las amenazas globales entre las cuales se cuentan la migración masiva, enfermedades nuevas y degradación medioambiental, el autor considera idónea la cooperación internacional, así como el mayor apoyo en el avance tecnológico y el ajuste al derecho internacional por parte de Estados Unidos para tratar estos asuntos.

\section{ENTRE LA VISIÓN MESIÁNICA Y LOS CAMBIOS MUNDIALES}

En la primera parte del libro, Sachs muestra, de manera crítica, lo que consideran las raíces his- tóricas de una visión mesiánica que da sustento al accionar militar supuestamente salvador de Estados Unidos, pero que en realidad lleva a la destrucción y al caos puesto que elimina de tajo los procesos y tradiciones de los diferentes territorios, y de los cuales América Latina no ha estado exento.

La guerra ayudó a Estados Unidos a salir de la crisis del 29 en parte por las demandas en ciencia y tecnología que produjo, y en parte porque no hubo destrucción de capital dentro de su territorio. Señala Sachs cómo a mitad del siglo xx Estados Unidos asume el liderazgo mundial de un mundo libre, no solo por el peso que tenía en la economía mundial, sino por su papel en la creación de organismos internacionales que respaldaban este propósito. Sin embargo, destaca de manera fehaciente que la otra cara de este liderazgo se define por el no acogimiento a las normas de dichos organismos como la ONU en situaciones que limitaban su accionar, la desestabilización de gobiernos, cambios de régimen y asesinatos de líderes de la mano de la CIA, y el derrocamiento de líderes y empobrecimiento de poblaciones en caso de que esto sirviera para los intereses económicos de las compañías norteamericanas (pp. 25-32).

De otra parte, Sachs señala la situación de Estados Unidos desde el siglo xIx hasta la actualidad, su pérdida de dominio a nivel mundial en distintos frentes y el papel que tiene China en estos momentos con respecto a su papel como promocionador de acuerdos comerciales y de integración. En ese sentido, señala las posibilidades que se le abren a los otros países del globo, en particular a los de Asia, al incrementarse los vínculos comerciales entre estos y con Europa. Así mismo, muestra 
cuál fue el papel que Estados Unidos tuvo en la estructuración de la economía de Rusia y las provocaciones que ha habido por parte de Estados Unidos que lo aíslan cada vez más en el contexto internacional.

Para Sachs el excepcionalismo de Trump es una versión más vulgar que la anterior, que se apoya en la intención de mantener el dominio militar, en el racismo y la política antiinmigrantes $y$, finalmente, en un populismo económico que protege a los más ricos (Sachs, 2018, pp. 38-42).

\section{NECESIDAD DE PONER FIN A LAS GUERRAS ESCOGIDAS}

En la segunda parte muestra, de manera clara, la contradicción entre lo que es la visión pacífica que los estadounidenses tienen sobre sí mismos y el real vínculo entre guerra y política exterior que se ha mantenido a lo largo de la historia. Las guerras que Estados Unidos ha librado son guerras de elección en donde prima su deseo manifiesto de expandir su presencia e influencia, puesto que tiene intereses bien marcados en los distintos territorios que van desde el petróleo de Medio Oriente hasta las tierras agrícolas en América Latina y el establecimiento de bases militares alrededor del mundo (pp. 66-68).

Para el caso muestra, entre otros, lo sucedido en las guerras de Vietnam y de Medio Oriente en donde Estados Unidos atacó primero y que estuvieron soportadas en mentiras y pruebas inexistentes, como en el caso de Irak en relación con las armas de destrucción masiva (Sachs, 2018, pp. 69-76). Con la excusa de mantener a Estados Unidos fuera de una nue- va guerra se atacan regiones. En este sentido, Sachs señala la responsabilidad que tuvieron los países europeos en el actual conflicto entre Israel y Palestina al recordar las promesas incumplidas que se hicieron a los habitantes de la región, desde antes de la segunda guerra mundial y urge por la retirada de Estados Unidos de los conflictos de Medio Oriente. A la vez, recuerda la posición internacional alrededor de la decisión del presidente Trump de reconocer unilateralmente a Jerusalén como capital de Israel, que aleja la posibilidad de llegar a una solución para Israel y Palestina (pp. 77-86).

De igual manera, Sachs llama la atención sobre las tensiones que generan la posibilidad de que se desate una conflagración mundial de dimensiones catastróficas y que amenacen la vida en el planeta, por lo que pone de relieve las tensiones con el gobierno de Corea del Norte. A su vez, el alto costo que tienen las cerca de 800 bases militares y la estrategia de dominio militar de Estados Unidos resultará poco benéfica para el país, no solo porque compite con un país de dimensiones superiores como China, sino porque la política completa lleva a un mayor déficit presupuestal y a recortes en ciencia y tecnología (pp. 97-102).

\section{LA DEFENSA ECONÓMICA}

En la tercera parte, Sachs analiza lo costoso de la política America First la cual, además de minar las posibilidades de innovación y creación, de riqueza y bienestar, se apoya en el desconocimiento de las implicaciones de las decisiones económicas y en la creencia del engaño de las contrapartes comerciales de Estados Unidos. Las medidas adoptadas no llevarán a la dis- 
minución del desempleo ni a la disminución de la desigualdad, puesto que se basa en las ganancias rápidas y en una mentalidad basada en la conspiración que tiene actualmente al debilitamiento de China como uno de sus principales caballos de batalla (pp. 103-104).

Una de las falacias en las que se apoya dicha política es en los beneficios sobre el empleo que trae la reversión de la deslocalización, realmente son muy bajos y demasiado costosos. Así, disminuir los gravámenes a los propietarios del capital lo que hace realmente es aumentar las cargas económicas para los trabajadores locales y generar descontento social e inestabilidad política. Además, los supuestos beneficios que se lograrían al recortar las contribuciones a la ONU realmente resultan insignificantes en relación con el monto del gasto militar, pero más perjudiciales que si se disminuyera este último, y aumentar el déficit presupuestario pone en aprietos a las generaciones futuras

$\mathrm{El}$ ataque a China y la creencia de que se debería presionar para que ingrese en una carrera armamentística resulta para Sachs un enfoque erróneo y peligroso. En particular, la economía china está madurando por lo que su crecimiento disminuye y unido a una gran población que está envejeciendo, las posibilidades de ser una amenaza para la seguridad de Estados Unidos o mundial no es tan cierta. Lo que le conviene más a Estados Unidos es cooperar con China, permitir la integración económica y política regional, aumentar la inversión en innovación, desarrollo y el liderazgo tecnológico, lo cual es rescatado por Sachs como una de las herramientas que le ayudaron a su crecimiento en tiempos pretéritos. Inte- gración que debe ser apoyada no solo en Asia sino en las demás partes del globo, incluido Medio Oriente y África.

\section{COOPERACIÓN Y DIPLOMACIA}

En la cuarta y última parte del libro Sachs sugiere las ventajas que tendría una política exterior más colaborativa, apegada a las reglas y normas de las Naciones Unidas.

Para llegar allá comienza mostrando una versión bastante amable de lo que fue la política estadounidense a mediados del siglo pasado, recalcando que el liderazgo no debe apoyarse en esquilmar a las otras naciones. Muestra que el monto de las ayudas de Estados Unidos para invertir en bienes públicos ha venido disminuyendo, así como el interés en apoyar a los países en vías de desarrollo para recuperarse. De igual forma, señala cómo aumentan las acciones basadas en el poder duro a costa del manejo de los instrumentos diplomáticos y el poco compromiso que ha mantenido desde finales de la década de 1970 en relación con los tratados internacionales en los que ha participado, siendo un ejemplo de estos la declaración de intención de retiro del Acuerdo Climático de París de 2015 (pp. 138-147).

Para Sachs, esta actitud de rechazo a los tratados globales hace que Estados Unidos pase de ser una nación líder a una deshonesta. En esa vía, recalca que la disminución del presupuesto para la onU es más perjudicial que benéfica para Estados Unidos y el planeta, y explica las desproporciones del gasto militar en Estados Unidos en relación con lo que corresponde a su aporte en el presupuesto de la ONU, 
el cual es una manera de prevenir conflictos y salvar vidas.

En términos de la política antiinmigración, Sachs recuerda que en buena medida las guerras y los problemas que padecen en este momento algunos países expulsores de población han sido instigadas por los mismos Estados Unidos. Esto incluye la guerra contra las drogas que afecta a los países de América Latina, los temores exagerados y alejados de la realidad sobre el islam, que se apoyan en la falta de educación de una parte de la población blanca que resulta ser la base electoral de Trump, y a la que alimenta además con el desprecio a la población hispana.

Finalmente, para lograr el desarrollo sostenible con la ayuda de la política exterior, Sachs recomienda: realizar actividades enfocadas en mejorar los servicios de salud y educación, ser razonables con el uso de la tierra, mejorar la infraestructura y el empleo, descarbonizar el sistema energético para evitar un desastre irreversible a nivel mundial, la resolución pacífica de conflictos con énfasis particular en la situación de Medio Oriente, el terminar las operaciones encubiertas de la cia, el uso de los avances en ciencia y tecnología para el progreso en donde las universidades juegan un papel central y hacer una reducción en el gasto militar del gobierno (Sachs, 2018, pp. 166-176).

A lo largo del escrito se evidencia que la política America First, "ampara una visión del mundo reduccionista que pretende dar validez a postulados ya superados [...] en donde despreciar las divergencias no solo no es pragmático sino peligroso" (Laborie, 2018, p. 14), para la humanidad en su conjunto sobre todo porque el mundo ha cambiado y se está en un punto en el que la demostración de fuerza y las amenazas podrán, en apariencia, ser válidas en algún contexto, pero en realidad resultan contraproducentes.

Sachs hace un llamado a la sensatez al recordar que el desarrollo sostenible no implica solo mayor riqueza, sino la posibilidad de vivir en una sociedad con mayor inclusión e igualdad, y en la que se proteja el medio ambiente. El desafío no debe recaer solo en Estados Unidos, aunque la cuestión es que este país lo permita y acepte que su visión guerrerista en verdad no ha traído los beneficios que se creen, aun para sus mismos habitantes, y que este es un momento en el que la cooperación es necesaria y benéfica para todos.

\section{REFERENCIAS}

Carrasco G., G. (2017). La política migratoria de Donald Trump. Alegatos, No. 95, México, enero/abril.

Laborie, M. (2018). America first ¿Un modelo válido de seguridad nacional para EE.uU.? Documentos de Opinión. Instituto Español de Estudios Estratégicos. Obtenido de http://www.ieee.es: http://www.ieee.es/Galerias/fichero/docs_opinion/2018/DIEEEO10-2018_Estrategia_us_MarioLaborie.pdf.

Sachs, J. D. (2018). A New Foreign Policy: Beyond American Exceptionalism. New York: Columbia University Press.

Sachs, J. D. (2014). La era del desarrollo sostenible. Bogotá: Planeta. 